\title{
Los valores éticos en la responsabilidad social corporativa*
}

\author{
Gómez Nieto Begoña** \\ Martínez Domínguez, Rocío**
}

Recibido: 2015-06-26 Enviado a pares: 2015-06-30

Aprobado por pares: 2015-08-05 Aceptado: 2015-08-15

\section{Resumen}

La significación de responsabilidad social corporativa (RSC) o empresa socialmente responsable (RSE) ha pasado de ser un concepto abstracto y mal entendido, a ser un apellido que otorga prestigio a las empresas que deciden adoptarlo. Las empresas han adoptado y adaptado esta concepción con el objetivo de seguir lucrándose con sus actividades empresariales, pero poseyendo un argumento perfecto para venderse ante una sociedad cada vez mejor educada en temas sociales y medioambientales: ser socialmente responsable o, lo que es lo mismo, buena con el entorno más próximo que le rodea y en el que crece.

Se puede afirmar que una empresa es socialmente responsable cuando su modelo de actuación promueve el desarrollo de prácticas transparentes en el foro interno y externo de la empresa, marco de actuación que no solo se limita al área de confort de la organización sino a un saber hacer ético. Los códigos éticos y corporativos deben ser accesibles y comunicados correctamente ante todos los públicos de una empresa.

El objetivo de este estudio se centra en analizar la relación existente entre la Ética y la RSC, ya que ambas deben ser inseparables en la construcción del eje transversal que recorre la estrategia organizacional. Se desarrolla una metodología de tipo cualitativo, justificado por el enfoque conceptual-teórico desde el punto de vista social, cultural y económico del tema objeto de estudio.Palabras clave: Homeland, primera temporada, política, análisis textual. Palabras clave: ética, responsabilidad social corporativa, competitividad, valor social, competitividad responsable.

* El artículo se enmarca dentro de una investigación más amplia sobre la comunicación online de la Responsabilidad Social Corporativa, que se llevó a cabo tomando como estudio de caso las empresas líderes del mercado minorista español

** Es doctora en Ciencias de la Información por el IE Universidad de Segovia y licenciada en Comunicación por la Universidad Complutense de Madrid. Ha trabajado como profesora en Publicidad y Relaciones Públicas, Periodismo y Comunicación Audiovisual de la Universidad Europea Miguel de Cervantes de Valladolid y también profesora de Periodismo en la Universidad de Valladolid.

Ha publicado más de una treintena de artículos fruto de sus líneas de investigación centradas en el ámbito de la comunicación corporativa, comunicación publicitaria, nuevas formas de comunicación publicitaria y comunicación periodística (ambient marketing, redes sociales, estructura de contenidos en webs, prensa escrita y publicidad...), varios capítulos de libro y dos libros. gomeznietob@gmail.com

*** Es licenciada en Publicidad y Relaciones Públicas por la Universidad Europea Miguel de Cervantes (Valladolid).gomeznietob@hmca.uva.es 


\title{
Ethical Values in Corporative Social Responsibility
}

\begin{abstract}
The significance of corporate social responsibility (CSR) or company socially person in charge (SRC) has happened of being an abstract concept and understood evil, to be a surname that gives prestige to the companies that decide to adopt it. The companies have adopted and adapted this conception with the aim to continue enriching itself with his managerial activities, but possessing a perfect argument to sell before an every time better company educated in social and environmental topics: to be socially responsible or, which is the same, good thing with the most next environment that him makes a detour and in the one that grows.

It is possible to affirm that a company is socially responsible when his model of action promotes the development of transparent practices in the internal and external forum of the company, frame of action that not only limits itself to the area of comfort of the organization but to one to be able to do ethically. The corporate codes of ethics must be accessible and communicated correctly before all the public ones of a company.

The aim of this study centres on analyzing the existing relation between the Ethics and the RSC, since both must be inseparable, in the construction of the transverse axis that crosses the strategy organizational. There develops a methodology of qualitative type, justified by the conceptual - theoretical approach from the social, cultural and economic point of view of the topic object of study.
\end{abstract}

Key words: Ethics, Corporate Social Responsibility, Competitiveness, Social value, Responsible competitiveness 


\section{Introducción y estado de la cuestión}

Una de las grandes máximas institucionales es que ningún profesional ha creado ni creará un negocio para perder dinero, pero sí es cierto que las motivaciones para la fundación de un proyecto empresarial cambian y se adaptan a las circunstancias del momento. Actualmente, nos desarrollamos en una economía globalizada que deriva en un mercado, empresas, intereses, públicos... que no responden a los criterios locales o nacionales, como ocurría hasta hace unas décadas, sino que responden a juicios de índole internacional. Todo ello está impregnado de unas demandas sociales que han permanecido latentes durante largos años pero que empiezan a ver la luz de manera acelerada. Esta realidad deriva en la necesidad de una concienciación social de todas las acciones empresariales que se desarrollan.

Arie de Geus ${ }^{1 *}$ señala que las compañías mueren porque sus directivos se centran exclusivamente en producir bienes y servicios, y se olvidan de que una empresa es una comunidad de seres humanos que está en el mundo de los negocios, cualquier negocio, para permanecer viva.

Las consecuencias medioambientales de las actividades comerciales de las empresas llevan poniendo en peligro la perdurabilidad del medioambiente tal y como lo conocemos. Y no solo eso, sino que se ha ido más allá. Ya no se exigen únicamente prácticas responsables de las compañías a nivel medioambiental sino también social. Las instituciones deben adquirir un compromiso con la comunidad en la que viven, porque son un ente social más con las mismas o incluso más responsabilidades sociales. Juan Romero, líder corporativo de Cemex, afirma (Pizzolante Negrón, 2009), que:

Ser líder en sustentabilidad es minimizar nuestra huella y maximizar la contribución positiva a la sociedad, a la vez que fortalecemos nuestra competitividad a largo plazo, haciendo que el mundo sea un mejor lugar para vivir todos nosotros y las generaciones por venir (p. 249).

La significación de responsabilidad social corporativa (RSC) o empresa socialmente responsable (RSE) ha pasado de ser un concepto abstracto y mal entendido, a ser un apellido que otorga prestigio a las empresas que deciden adoptarlo. Pero la evolución no se detiene en este punto. Las empresas han adoptado y adaptado esta concepción con el objetivo de seguir lucrándose con sus actividades empresariales, pero poseyendo un argumento perfecto para venderse ante una sociedad cada vez mejor educada en temas sociales y medioambientales: ser socialmente responsable o, lo que es lo mismo, buena con el entorno más próximo que le rodea y en el que crece.

Concretamente sobre la ética, la ética empresarial y la responsabilidad social empresarial se vierte variedad de discusiones, sin llegar a definir de manera exacta y definitiva lo que significan. Son tres temas que por más que se discutan siempre generarán polémica y discrepancias por sus características particulares y su susceptibilidad a ser interpretados desde varios puntos de vista (Socorro, 2009).

1 Autor de The Living Company 
En pleno siglo XXI puede afirmarse con total rotundidad que la RSC es un valor obligatorio que deben mostrar las empresas tanto en su ámbito externo como en el interno, debe ser un elemento que impregne a su esencia y no un complemento que se limita al cumplimiento de unos estándares mínimos, y debe ir de la mano de la ética. Prueba de ella son todas las compañías que han hecho de un concepto novedoso una oportunidad de negocio. Es necesario dedicar tiempo y esfuerzos a cuidar un entorno que se modifica continuamente en función de nuestros intereses sin importar las consecuencias que le causamos, por lo que es precisa una concienciación social global que enseñe el respeto por lo que es nuestro y su buen uso, para que las generaciones que están por venir puedan disfrutar, como mínimo, de aquello que hemos gozado las civilizaciones del momento (Abascal, 2005:135).

Una vez entendida la necesidad y el motivo del nacimiento de esta nueva visión de generar riqueza, resultan llamativos los diferentes métodos que han seguido las empresas para poder ser consideradas responsables socialmente. Si a este contexto se le suman dos elementos más como son el hecho de que una compañía hasta cuando no comunica está comunicando, y todas las nuevas herramientas de comunicación que existen gracias a la revolución de las comunicaciones, se obtiene una ecuación muy interesante difícil de manejar.

Afirmaba Abraham Lincoln, que si pudiéramos saber primero en dónde estamos y hacia dónde nos dirigimos, podríamos juzgar mejor qué hacer y cómo hacerlo. A través del análisis derivado de la aplicación de diferentes métodos de estudio, se obtendrá dónde estamos en el largo camino de una buena implantación y comunicación de la RSE en las empresas, y hacia dónde nos queremos dirigir que se estipula en las metas que la organización se marca en el medio y largo plazo. De este modo, será mucho más sencilla, práctica y plausible la definición de estrategias operativas integrales que permitan alcanzar los objetivos marcados, así como las actividades concretas para la consecución de los mismos.

\section{Objetivos}

El objetivo principal de este estudio se centra en analizar la relación existente entre la Ética, en toda su extensión (formas, procedimientos y modos de actuar de la organización ante los distintos públicos o stakeholders: clientes o usuarios, empleados, instituciones públicas y privadas, medios de comunicación y sociedad en general) y la Responsabilidad Social Corporativa. Ambas deben ser inseparables en la construcción del eje transversal, que recorre la estrategia organizacional.

Como objetivos secundarios, se establecen:

La profundización en la relación ciudadano-empresa, ya que la organización forma parte de una comunidad en la que está inserto también el ciudadano, y de esta relación y de la aceptación del ciudadano de la empresa como ente responsable, dependerá en gran medida el éxito o fracaso de la organización en ese entorno concreto. 
El análisis de la unión entre organización responsable y competitividad, ya que el fin último de una empresa es ser competitiva en un entorno cada vez más global, y obtener beneficios económicos que le garanticen su supervivencia. Las actuaciones y comportamientos responsables ante la sociedad le pueden ayudar a conseguir este fin, si realiza una correcta gestión y comunicación de las mismas.

\section{Metodología}

En este estudio se ha aplicado una metodología mixta: conceptual/teórica y análisis de contenido. En primer lugar se desarrolla una metodología conceptual, puesto que se ha revisado en profundidad bibliografía, artículos científicos, estudios, datos sobre el concepto de RSC y los valores éticos, y de análisis de contenido, puesto que se han analizado informes, estudios de expertos del ámbito nacional e internacional para determinar la evolución experimentada por la RSC desde varios enfoques: económico, social, cultural. Este planteamiento explica el uso de un análisis de contenido (Van Dijk, 2003:149), que identifique la elección de temas, proposiciones, para el estudio de la RSC en relación con la Ética como elemento clave en la estrategia de las organizaciones.

\section{Sobre el concepto de responsabilidad social corporativa}

Existe una cierta confusión terminológica con respecto al término responsabilidad corporativa, ya que se habla indistintamente de responsabilidad social empresarial, responsabilidad social corporativa o responsabilidad empresarial. Y, además, se confunde con otros términos como desarrollo sostenible, sostenibilidad y similares. En este caso tomamos como referencia la definición aportada por la Comisión Europea en el Libro verde en 2001, que define la responsabilidad corporativa como "la integración voluntaria, por parte de las empresas, de las preocupaciones sociales y medioambientales en sus operaciones comerciales y sus relaciones con sus interlocutores" (Libro verde, 2001). Se concibe como una contribución empresarial al desarrollo sostenible. En líneas generales puede afirmarse que la responsabilidad corporativa se ha convertido en algo más que cumplir o acatar las exigencias legales que se estipulan en este campo; es ir más allá integrando la RC en los valores, el gobierno, la estrategia y las operaciones en general de las empresas.

El cambio en la concepción de empresa es doble. Por un lado, se apela a los motivos éticos, pues la empresa es la institución social con mayor capacidad de innovación y de contribuir a un cambio positivo en la actual situación económica, social y medioambiental de nuestro planeta. Y por otro, una empresa se crea con el fin de que perdure el máximo de tiempo posible, por lo que la contribución de la empresa a la sostenibilidad del entorno en el que se desarrolla y compite se convierte en un elemento fundamental de su razón de ser.

\section{Responsabilidad social corporativa y ética}

Algunos autores como Monzón y Chaves (2011) fijan el origen de la RSE en la década de los treinta, y otros, en los setenta, pero lo cierto es que desde los años noventa este concepto ha ido cobrando fuerza y evolucionado constantemente, tras el advenimiento 
de la globalización, el aceleramiento de la actividad económica, la conciencia ecológica y el desarrollo de nuevas tecnologías.

Una empresa es socialmente responsable cuando su modelo de actuación (su buen gobierno) promueve el desarrollo de prácticas transparentes en el foro interno y en el externo de la empresa. Este marco de actuación no se limita solo al área de confort de la organización o a los resquicios que no se recogen en las leyes, sino a un saber hacer ético.

En toda ética aplicada, las ideas y propuestas deben pasar siempre el test de aplicabilidad, la prueba de su posible realización práctica. En este caso, esto significa que la cuestión del porqué adoptar la responsabilidad social de la empresa no se puede separar del cómo hacerlo. Al igual que ocurre con todo tipo de saberes prácticos, que nos ayudan a tomar buenas decisiones, la falta de claridad en los conceptos conlleva siempre serios impedimentos en los comportamientos posteriores (García-Mazá, 2004:170). De manera que solo se puede hablar de credibilidad o legitimidad social cuando la organización es capaz desarrollar un contexto de diálogo continuo con todos sus públicos de manera sostenida y constante en el tiempo, manteniendo a todos en consenso.

Los códigos éticos corporativos y de conducta en el nivel interno derivan en un beneficio porque establecen la búsqueda de los máximos estándares de calidad en los productos y servicios, y en el avance tecnológico. Las empresas conciben esta declaración de principios como un activo intocable que ayuda a la consecución de la identidad, la credibilidad y la personalidad.

Los valores éticos deben impregnar cada una de las piezas que componen el engranaje de una empresa, incluyendo, por supuesto, a todo el equipo directivo. La existencia de un directivo ético facilita la conexión entre los valores de la sociedad y los de la empresa, aunque esto no asegura el desarrollo de una ética profesional, pues la orientación hacia un management más ético y responsable es algo optativo desde una visión sociocultural y perspectiva funcional (Abascal, 2005:77). Prueba de ello es que en muchas ocasiones la cultura es el resultado del trabajo y de la cooperación con otras entidades y personas, origen de toda ética. Y esta ética social es la que evoluciona en la ética de la comunicación.

La RSC queda definida como herramienta de transparencia, al igual que la comunicación lo es. Para Herranz de la Casa (2007:28), gestionar la comunicación puede ser una estrategia fundamental para generar transparencia dentro y fuera de las organizaciones y también en el caso de las no lucrativas, y, en consecuencia, puede ser una herramienta para mejorar la imagen como percepción pública a corto plazo; puede aumentar la confianza como sentimiento de credibilidad a medio plazo; y consolidar la reputación como reconocimiento a largo plazo. Dadas las circunstancias de la sociedad actual, es necesaria la búsqueda de un modelo de gestión de la comunicación para la transparencia que sintetice una filosofía de comunicar para ser transparente. Un modelo que se base en la fórmula que verifica la potencialidad de la sinergia entre comunicación y transparencia: Transparencia (valor) X Comunicación (estrategia y herramienta) = Imagen (percepción), Confianza (sentimiento), Reputación (reconocimiento). 
Definitivamente, el valor de la RSE está relacionado con los beneficios que esta representa no solo para la organización, sino también para los grupos de interés. Adicionalmente, se trata de medir el impacto de las actividades de una organización no solamente desde el punto de vista económico sino de aquellos beneficios intangibles de la RSE; así lo señala Manuela Weber en su artículo "Revelar el potencial empresarial de la RSC: Cómo pueden las empresas evaluar los beneficios específicos de la RSC para la empresa".

Por otra parte, tradicionalmente se señalan como beneficios de la RSE, la mejora de la imagen corporativa y la reputación empresarial, la reducción de costos de operación, el fortalecimiento de la capacidad de las organizaciones de reclutar y retener mejores empleados, fortalecimiento de la relación con la comunidad, el fortalecimiento de la lealtad de los consumidores, la mejora la calidad y la productividad, y el aumento de la rentabilidad, entre otros tantos (Puterman, 2011).

Toda gran marca cuenta con un respaldo importante de planteamientos éticos que le otorgan capacidad para hacer bien las cosas aportando calidad a sus productos y servicios, y tratar a los clientes actuales y potenciales de la manera más idónea para mantenerlos en el medio y largo plazo. Por ello las empresas han introducido paulatinamente programas éticos en todas sus acciones para alcanzar un mayor rendimiento. La AMA, American Marketing Association, ha elaborado un código ético reflejado en códigos de conducta que las empresas han aplicado en su organización.

Según Abascal (2005:121) para comprender el contenido de esta ética empresarial hay que partir de dos postulados:

1. La ética de empresa tiene el mismo signo que la ética general, no pueden ser diferentes.

2. La empresa no tiene responsabilidad ética por sí misma, sino que es la que poseen los miembros que la constituyen, administran y dirigen.

Los códigos de conducta son herramientas que explican y detallan en qué consiste la actuación ética por parte de la empresa; y aclaran a los trabajadores sobre sus derechos y obligaciones.

El diseño del modelo ético se formula de acuerdo con sus públicos de interés:

- Empleados. Las relaciones entre la alta jerarquía de la empresa y el empleado deben realizarse desde la dignidad humana. Aquí se incluyen requisitos mínimos como un salario justo, trato correcto a los trabajadores, contrataciones responsables...

- Clientes. Estos justificarán su fidelidad a la compañía si la empresa consigue a través de sus productos que el consumidor esté satisfecho, garantía de calidad de los productos y servicio de pos-venta de calidad.

- Competidores. Todas las empresas deben comercializar bajo unas mismas normas y políticas de precios que deben respetarse. Y ser transparentes en cuanto a la competitividad de productos y servicios, uso leal de informaciones sin ánimo de perjudicar al competidor y transparencia en cuanto a las características de los productos y servicios propios. 
- Proveedores y distribuidores. Este colectivo debe cumplir con los mismos requisitos que la propia compañía. Su relación se basa en el respeto mutuo, las negociaciones deben ser legales y leales con carácter de medio y largo plazo y se debe evitar el enfrentamiento directo entre los competidores.

- Socios y accionistas. Deben estar al corriente de los principios y valores por los que se rige la entidad, por lo que la empresa debe facilitarles todo tipo de documentación.

- Comunidad y medio ambiente. El desarrollo de una relación empresa-comunidad es necesario, así como el compromiso voluntario de salvaguardar el medioambiente dentro de lo posible.

De modo que los códigos de conducta recogen los valores, la normativa y principios que las empresas establecen como propias y que las adoptan en su estructura básica, aplicándolas posteriormente a todas sus ramificaciones.

Muchos conceptos éticos con los que debe cumplir la empresa no se encuentran recogidos en las leyes, y tanto las propias instituciones como las de carácter legal necesitan de unos instrumentos que les ayuden a tomar decisiones moralmente buenas.

Parece obvio que la clave de una gestión empresarial ética parte de pensar, actuar y diseñar acciones que estén fundadas en un mínimo de moral y que los empleados reflejen en sus actividades diarias solidaridad, responsabilidad social y la búsqueda del bien común. Su razón de actuar debe basarse en la honestidad. Uno de los instrumentos clave para difundir y recordar todos estos conceptos éticos es la comunicación, que debe ser fluida, flexible, actualizada y permanente. Con ello se consigue que exista entre empleados, departamentos y clientes una comunicación real y bien realizada. También informaciones basadas en la veracidad y transparencia extendida a todos los empleados de la empresa. Y se evita la falta de información para que los empleados se sientan seguros y valorados. Debido a esta necesidad de hacer de la dimensión moral el enfoque principal de las empresas, surge la responsabilidad social basada en dos pilares: como contrato social, como mecanismo para demostrar que la empresa actúa de acuerdo con los valores de la sociedad; y como agencia moral, reforzar los valores a la hora de tomar las decisiones.

Para Abascal (2005:136) es importante distinguir entre el valor y la ética. Por valor se entiende el conjunto de valores a los que la empresa está ligada y con base en los cuales toma las decisiones, valores pensados y estructurados. Y por ética, que las decisiones empresariales responden a una ética útil pues el objetivo final es conseguir un mejor beneficio económico.

La ética se ha convertido en un elemento más que ayuda a la sustentabilidad de la empresa en el largo plazo, pues creando un clima laboral exento de problemas y estableciendo relaciones de calidad con los públicos de interés se obtiene una coexistencia pacífica en el entorno. 
Según Pacheco (2005:137), la empresa está considerada como una institución social que responde a una serie de compromisos que avalan su ética en su rentabilidad:

- Aportando productos y servicios útiles para la sociedad.

- Desarrollo local y comunitario mediante la creación de puestos de trabajo que permiten el desarrollo de las personas.

- Generando riqueza y un reparto equitativo de la misma.

- Alimentando la sustentabilidad clave de éxito a largo plazo.

En resumen, puede afirmarse que la empresa debe estar definida y comportarse de acuerdo con un buen código ético que se fundamenta en

- Relaciones humanas en la empresa: clima laboral de armonía en el que los empleados se sienten valorados, y por tanto, satisfechos y motivados.

- Relaciones con las entidades comerciales: se debe exigir un mínimo a los proveedores con los que se negocia, es decir, su declaración de principios éticos debe estar en consonancia con los propios.

- Relaciones con los consumidores: crear relaciones de entendimiento y comprensión. La empresa debe mostrar una actitud colaboradora basada en la confianza y servicio conseguido mediante el diseño, creación, producción y distribución de bienes y servicios que satisfacen sus necesidades; políticas de calidad y seguridad que garanticen unos estándares mínimos e informaciones transparentes sobre los productos y servicios ofrecidos. También son importantes las relaciones con el Estado y las leyes: cumplir con las exigencias legales requeridas, y las relaciones con los competidores: competitividad responsable. La ética no solo se presenta como la esencia sobre la que se deben fundamentar todas las relaciones que mantiene la empresa con sus diferentes públicos objetivos, sino que una sociedad cada vez más exigente y responsable demanda una actitud más comprometida por parte de las instituciones. Esta actitud es lo que se entiende hoy en día como responsabilidad social corporativa.

\section{El concepto de competitividad responsable}

La competitividad responsable es el punto de partida para alimentar el crecimiento y reforzar las empresas, afianzar el bienestar social a través de una correcta gestión del capital humano que integran las organizaciones. Para ello se debe participar en la búsqueda e implantación de soluciones atendiendo a las diferencias que existen.

Todas estas actividades deben estar impregnadas de transparencia, pues la competitividad responsable implica una nueva concepción y fuente de riqueza, ya que no solo se cultiva a la empresa como tal, sino a su labor social como agente que participa en la comunidad.

Para lograr un adecuado desarrollo de esta competitividad responsable son varios los documentos que se han ido negociando y elaborando a lo largo de los años. Todos 
ellos han sido propuestos por la Organización Internacional del Trabajo y la OCDE. También se tiene en cuenta una serie de normas publicadas por la Comisión de Derechos Humanos de las Naciones Unidas y los documentos divulgados la Subcomisión de la ONU para la Promoción y la Protección de los Derechos Humano titulados Normas sobre las responsabilidades de las empresas transnacionales y otras empresas comerciales, en la esfera de los derechos humanos (Negrón, 2009:229).

Todos estos documentos no tienen ningún poder jurídico por lo que su incumplimiento por parte de las empresas se limita a una falta de responsabilidad social en el nivel mundial, pero en ningún caso, se ve castigada con sanciones económicas o de cualquier otra clase. Todos estos documentos son herramientas que las empresas libremente deciden asumir e interiorizar dentro de su organización, y que implican la aceptación del Pacto Global de Naciones Unidas en su estrategia y en cada una de las actividades que desarrolla. Es importante destacar que la aceptación de este contenido no conlleva una certificación o la adquisición de normas legales, sino que se concibe como un compromiso que adquiere la organización libremente. Lo implanta como un proceso de evaluación que va estableciendo paulatinamente estos principios en sus actividades diarias.

Por último, debe ir informando con transparencia sobre los progresos que va realizando.

No se debe olvidar que la responsabilidad social implica a todas las empresas de la sociedad que aportan un valor añadido a la sociedad, independientemente de su intención económica (con o sin ánimo de lucro).

La Comisión Europea sostiene en el Libro verde de la RSC (2001), que:

La responsabilidad social de las empresas, no se debe considerar sustitutiva de la reglamentación o legislación sobre los derechos sociales o normas medioambientales, ni permite soslayar la elaboración de nuevas normas apropiadas. En los países que carecen de tales reglamentaciones, los esfuerzos deben centrarse en la instauración del marco legislativo o reglamentario adecuado, a fin de definir un entorno uniforme a partir del cual desarrollar prácticas socialmente responsables.

De acuerdo con este postulado, Jiménez (2007:164) establece que el interés por la Responsabilidad Social Empresarial surge por tres enfoques que no se ajustan exactamente a lo estipulado por la Comisión Europea:

a. Las regulaciones voluntarias pueden ser entendidas y elaboradas como un intento de las empresas para escapar de las regulaciones legales obligatorias.

b. Las regulaciones voluntarias son la respuesta a las presiones y el interés que las políticas empresariales despiertan entre los consumidores y ciudadanos en los países de desarrollo, con el crecimiento de la transparencia informativa.

c. Los escándalos contable-financieros de las empresas han llevado a que las empresas tomen interés por asuntos de índole no financiera como la calidad de las prácticas del 
gobierno y el análisis de las prácticas de responsabilidad social a la hora de construir valor. Este hecho desembocó en que cada empresa desarrollara su propio código de conducta que implantaría en sus delegaciones independientemente del ámbito geográfico en el que se encontraran, ignorando los "postulados oficiales" que se hacían desde las reconocidas entidades europeas.

Fundemas, la Fundación Empresarial para la Acción Social, publicó ya en el año 2007 el Índice de Competitividad Responsable elaborado por la ONG Británica AccountAbility. En él se exponía que los mercados estaban ya cada vez más dispuestos a comerciar con países y empresas socialmente responsables, y los banqueros aconsejaban a sus clientes que invirtieran en empresas que desarrollaran esta práctica. Este estudio pone en relación dos variables. Por un lado, los componentes de la acción del negocio como el Índice de Competitividad Responsable que es la combinación de los índices elaborados por el Foro Económico Mundial; y por otro lado, indicadores relacionados con el análisis de las políticas públicas (limitaciones a los derechos de los trabajadores en las empresas, tratados internacionales...), acciones propias del negocio (eficiencia de las Juntas Directivas, comportamientos éticos, sueldos...) y temas vinculados al entorno social, los facilitadores sociales (corrupción de los diferentes sectores, libertades civiles...).

Se estudian cada una de estas variables en cada uno de los países y regiones de modo que se obtiene un informe que los recoge y que permite la comparación. De esta categorización se distinguen cuatro grandes grupos o clusters que son:

- Starters: los países con más baja puntuación. Se caracterizan por empezar a poner en marcha políticas básicas y tratados que hablan sobre la salud laboral y la libre organización de negocios, entre otros asuntos.

- Compliers: su cometido es demostrar un progreso en la calidad internacional de sus empresas y sus juntas directivas. Son países que están comenzando a hacerse con cuotas de mercado de las cadenas globales de proveedores que cada vez están más concienciados respecto a la responsabilidad social.

- Asserters: se describen como los países que están creando marcas de fábrica nacional que desarrollan prácticas responsables del negocio para atraer la inversión extranjera y conseguir así, la promoción de la primera generación de productos globales y marcas de fábrica corporativas.

- Innovators: países que trabajan en la consolidación de una visión responsable en la base de sus economías domésticas, para cumplir con las estrategias diseñadas y sostenibles y con las regulaciones de responsabilidad corporativa.

En líneas generales, puede desprenderse la gran importancia que está adquiriendo la sociedad civil, la cual es capaz de ejercer la presión necesaria para obtener de las organizaciones un compromiso y un desarrollo de políticas cada vez más orientadas a la responsabilidad social, incluso en tiempos de crisis.

Existen empresas que en medio de la crisis han demostrado mantener una alta cultura 
de RSE en España, siendo ahora un momento esencial, para una actuación pública en la materia con medidas precisas y apropiadas para contrarrestar los impactos, ya que es cierto que no se llega a las crisis económica por azar o mala suerte, sino por un cúmulo de muchas irresponsabilidades ejercidas donde seguramente han sido unos más culpables que otros, pero cierto que cada quién tiene su grado de responsabilidad; basta traer a la memoria casos como Enron/Andersen, y el caso Lehman Brother, que con una historia de 160 años de transcendencia en el sector financiero, en el 2008, como consecuencia de la codicia desenfrenada, ha destruido personas, empresas y buena parte de la economía mundial en un efecto de juego de dominó, donde los valores como justicia social, valor de retorno social, responsabilidad de gestión no fueron fundamentales.

La correlación directa entre la ética y la RSE ante la crisis toma un mayor fundamento, más que teórico, de urgente aplicabilidad, cuando los códigos de ética, las normas de transparencia, la incorporación de nuevas tecnologías al gobierno de las cooperativas de crédito y las entidades financieras, y la Ley de Transparencia son pilares básicos para la cultura corporativa empresarial en la mitigación de riesgos e imagen de las organizaciones (Vañó, 2004).

\section{Sobre la ciudadanía global corporativa}

Esta nueva realidad de la competitividad responsable genera en los años 80 un nuevo modelo de ciudadanos en las empresas que afecta tanto la visión como la misión de las mismas, evolucionando hacia el concepto de ciudadano corporativo que implica asumir las responsabilidades sociales de la empresa como parte de las propias.

Es muy importante la asimilación de este hecho porque ciudadanía corporativa hace alusión a la responsabilidad social empresarial, pues este nuevo ciudadano-empresa, además de cumplir con sus responsabilidades y derechos, lo hace de manera responsable en el contexto de la sociedad en la que desarrolla su actividad.

El ciudadano corporativo asume el nuevo estado de conciencia (que desarrollan las empresas) como el impacto positivo o negativo que conlleva su operación, con un reconocimiento sobre el impacto de la innovación, la calidad de su operación y el desarrollo de sus productos, una forma de actuar que va más allá de los simples planes estratégicos diseñados por la empresa, y que debe adecuarse a los productos o servicios que oferta en el mercado (Negrón, 2009:240).

De manera que cuando una empresa es socialmente responsable lo es en su conjunto, la empresa actúa como tal, ofrece productos y servicios que se adecuan a esa responsabilidad social, informa sobre lo que acontece a sus stakeholders, se compromete con la comunidad (no de manera filantrópica y esporádica), y se impregna cada una de las partes que forma la estructura de organización de esta esencia y buen hacer social responsable. Por ello es importante desarrollar, paralelamente a este proyecto social empresarial, un proceso de autoevaluación y crítica, que vigile aquello que se dice que se hace, y aquello que realmente se hace. 
De acuerdo con Domínguez Martín (2011:59), la globalización de las oportunidades para las empresas no puede hacerse sin la correspondiente globalización de sus responsabilidades sociales.

Para Porter y Kramer (2006:88), la RSE, no es un modelo de gestión más sino una forma de concebir el negocio y su estrategia sin abandonar el logro de los beneficios considerando que su desarrollo económico debe ir unido a mejoras para la sociedad, y es inseparable de las relaciones de confianza con los stakeholders y sus requerimientos.

\section{Microética y macroética}

Son varios los motivos por los cuales las empresas deben ver la RSC como una ventaja competitiva que pueden y deben explotar, consiguiendo así un doble beneficio, para su propio ejercicio y para el bien común. Estas razones son:

- La empresa es un agente social más de la sociedad en la que se desarrolla y crece.

- La "empresa" es el conjunto de todos sus públicos de interés: accionistas y propietarios, pero también clientes, consumidores, proveedores, empleados y la comunidad local.

- Una vez adoptada y adapta la RSC al modelo de negocio que se tiene, se obtienen resultados positivos a medio y largo plazo.

- Como institución social la empresa dispone de medios (materiales, económicos y humanos) para contribuir al bien común.

- Se producirán sanciones públicas a todas aquellas organizaciones que no asuman el mínimo de responsabilidades exigidas.

Según Díez y Redondo (2009), para poder entender los motivos por los cuales las empresas no apuestan por la RSC es preciso diferenciar entre microética y macroética.

Dentro de la microética se incluyen los siguientes aspectos:

- Aunque la implantación de RSC en la empresa tenga rentabilidad a corto y largo plazo, la adopción de medidas supone un coste en el corto plazo.

- Es fundamental que el comportamiento de las altas esferas sea ético para que mediante un proceso de aprendizaje se contagie al resto del capital humano.

- Medidas cortoplacistas muy tentadoras económicamente se contradicen con las políticas de RSC.

- Herramientas para medir y evaluar la rentabilidad de estas actividades morales, más allá de que encarnan una contribución al bien social.

- El concepto de ética es aplicable a las personas que integran la empresa y no a la empresa como tal (es un ente abstracto). 
- Involucración de la alta dirección reflejada en proyectos y actividades concretas.

Desde la macroética se aprecia:

- Coexistencia de la moralidad y legalidad. Situaciones a las que la empresa debe hacer frente y no están recogidas en la ley son el punto de inflexión para demostrar su compromiso de RSC.

- Poder beneficiarse de una acción calificada como poco moral debido a que la sanción que conlleva es asumible y más barata que cumplir con lo que se considera ético socialmente.

- Dificultad de homogeneizar los valores de la sociedad en su conjunto puesto que está constituida por muchos públicos con intereses contradictorios en la mayoría de las ocasiones.

- La ciudadanía socialmente responsable debe apoyar las prácticas de las empresas asumiendo el coste adicional que supone esta práctica en las empresas, que se muestra en el precio de los productos y servicios que ofrece.

- En mercados altamente competitivos en los que se deben destinar todas las partidas presupuestarias a mantener/mejorar el posicionamiento, es difícil que las empresas destinen dinero a estas acciones.

- Las grandes empresas que se erigen como líderes en sus sectores pueden desarrollar proyectos de RSC porque tiene medios. Pero las pymes necesitan de ayudas públicas y organismos no gubernamentales para poder implantarlas.

\section{Conclusiones}

La significación de responsabilidad social corporativa (RSC) o empresa socialmente responsable (RSE) ha pasado de ser un concepto abstracto y mal entendido, a ser un apellido que otorga prestigio a las empresas que deciden adoptarlo. Pero la evolución no se detiene en este punto. Las empresas han adoptado y adaptado esta concepción con el objetivo de seguir lucrándose con sus actividades empresariales, pero poseyendo un argumento perfecto para venderse ante una sociedad cada vez mejor educada en temas sociales y medioambientales: ser socialmente responsable o, lo que es lo mismo, buena con el entorno más próximo que le rodea y en el que crece.

Se puede afirmar que una empresa es socialmente responsable cuando su modelo de actuación promueve el desarrollo de prácticas transparentes en el foro interno y externo de la empresa, marco de actuación que no solo se limita al área de confort de la organización sino a un saber hacer ético. Los códigos éticos y corporativos deben ser accesibles y comunicados correctamente ante todos los públicos de una empresa.

Debe haber una evolución desde la responsabilidad social corporativa hacia la empresa socialmente responsable, que la RSE sea la esencia de toda la estructura organizativa lo 
que implica el desarrollo de una competitividad responsable y una educación social para obtener una ciudadanía global corporativa.

Muchas organizaciones empresariales, sin importar el tamaño de sus activos, se han encarrilado y han priorizado la acumulación de riqueza sin medida, utilizando el materialismo y el utilitarismo que se han consolidado en el ámbito internacional como corrientes de pensamiento habitual, en las que se margina la importancia de las responsabilidades morales del individuo. Ello ha dado como resultado una falta de confianza en los diferentes stakeholders y en el desarrollo organizacional empresarial, lo que afecta a todos. De allí que se hayan abierto interrogantes sobre la responsabilidad social empresarial (RSE) y sobre el valor de la ética como fundamento de aquella, ya que "la economía social es el germen de la responsabilidad social" (Monzón, 2014). Es este, entonces, el momento de tomar decisiones sobre la aplicación de esta temática.

La RSC ya no es una opción de la que se puede hacer o no uso, puesto que es una exigencia de la sociedad a todo tipo de organizaciones, tanto del sector público como privado. Una manera de avanzar puede ser buscar activamente lo que la responsabilidad corporativa puede significar de valor compartido. En una sociedad cambiante y global no existe un mando único, pero sí existen posiciones interrelacionadas, incluso convenidas y corresponsables. El buen gobierno genera necesariamente responsabilidad social siempre que el fin que se pretenda alcanzar reconozca el interés (el bien) de la sociedad y responda ante ella, así como ante las otras partes afectadas por su acción (Lizcano, 2006:34).

Antonio Argandoña, en su ensayo La dimensión ética de la crisis financiera (2010), pone de manifiesto que la crisis causada por la simple búsqueda de beneficios máximos, con perversión al estructurarse el mecanismo financiero especulativo, de un excesivo apalancamiento de las operaciones fuera de balance y la consiguiente asunción de excesivo riesgos hasta los conflictos de intereses permitidos, han incluido comportamientos de publicidades engañosas, imprudencias, codicias, arrogancias, conflicto de intereses, fraudes, incentivos perversos, regulaciones y leyes, que incluyen también la templanza en la capacidad de frenar el deseo de éxito de riqueza o reconocimiento social; porque es muy probable que muchos directivos y organismos de control se dieron cuenta lo que estaba ocurriendo, pero no fueron capaces de tomar decisiones para no poner en peligro su carrera o remuneración, que complicaría su vida profesional, gubernamental, o empresarial.

El buen comportamiento genera confianza en su dimensión ética, y esta se transmite del plano personal al organizacional y de este al entorno, mientras que el comportamiento éticamente reprobable destruye confianza (Guillén, 2006:308-309).

De acuerdo con Campoverde (2014), las empresas no siempre quiebran por falta de recursos sino por su administración frente a los clientes, los colaboradores, la comunidad y el Estado. Es el momento de que los valores éticos y la responsabilidad social corporativa estén presentes en la esencia de la estrategia empresarial, ya que pueden ayudar, sin duda, al cumplimiento de los objetivos de la organización, independientemente de su tamaño y ámbito de actuación. 


\section{Referencias bibliográficas}

Abascal Rojas, F. (2005). Marketing social y ética empresarial. Madrid: ESIC.

Argandoña, A. (2010). La dimensión ética de la crisis financiera. IESE Busines School. Universidad de Navarra. Catedra "La Caixa" de Responsabilidad Social de la Empresa y Gobierno Corporativo. Documento de Investigación DI-872, julio 2010.

Campoverde, F. (2014). Ética como fundamento de la Responsabilidad Social Empresarial. Recuperado el 11 de agosto de 2015, de http://www.gestiopolis.com/etica-como-fundamento-de-laresponsabilidad-social-empresarial/

Domínguez Martín, R. (2011). La responsabilidad social global empresarial (RSGE): el sector privado y la lucha contra la pobreza. Revista del Ministerio de Trabajo e Inmigración, n. ${ }^{\circ}$ 76. Recuperado el 12 de agosto de 2015, de http://www.empleo.gob.es/es/publica/pub_electronicas/destacadas/revista/ numeros/76/est03.pdf

FUNDEMAS (2007). Competitividad Responsable, nueva fuente de riqueza. Boletín N. ${ }^{\circ} 111,14$ de agosto.

García-Marzá, D. (2004). Ética empresarial del diálogo a la confianza. Madrid: Editorial Trotta.

Guillén Parra, M. (2006). Ética y responsabilidad social. Ética en las organizaciones. Construyendo confianza. México: Editorial Person Hall.

Herranz de la Casa, J. M. (2007). La gestión de la comunicación como elemento generador de transparencia en las organizaciones no lucrativas. CIRIEC-España, n. ${ }^{\circ}$ 57. Recuperado el 11 de agosto de 2015, de http:// www.ciriec-revistaeconomia.es/banco/5701_Herranz.pdf

Jiménez Fernández, J. C. (2007). La responsabilidad social de las empresas (RSE). Cómo entenderla, cómo afrontarla. Una perspectiva sindical. Albacete: Altaban Ediciones.

Libro Verde sobre la RSE (2001). Recuperado el 07 de agosto de 2015, de http://observatoriorsc.org/ libro-verde-fomentar-un-marco-europeo-para-la-responsabilidad-social-de-las-empresas/

Lizcano, J. L. (2006). Análisis de la responsabilidad social corporativa de las grandes ciudades en España, en Cueto, C. Recuperado el 11 de agosto de 2015, https://books.google.es/books?id=29bOBOAAOBAJEpg $=$ PA37Elpg $=$ PA37Edq $=$ medici\%C3\%B3n + de + la + rscEsource $=$ blEots $=1 \mathrm{mLdz9PrDYEsig}=-1 \mathrm{qJ}$ t9RnDnhwSs8SxJVnUbAG2AEhl = es\&sa =XEved =0CEMO6AEwAjgKahUKEwi2t8Wy 1 aDHAhULSRo KHUv-Dlk\#v= onepageEq = medici\%C3\%B3n\%20de\%20la\%20rscEf $=$ false

Monzón Campos, J. L. (2010). La economía social, germen de la responsabilidad social corporativa, responsabilidad social: una reflexión global sobre la RSE. Coord. por Juan José Almagro, José Antonio Garmendia Martínez, Isabel de la Torre Prados.

Monzón, J. L. y Chaves, R. (2011). The social economy: an international perspective. Introduction. Revista CIRIEC-España, n. ${ }^{\circ}$ 73, Special Issue, October 2011, pp.5-8. Recuperado el 12 de agosto de 2015, de http://www.ciriec-revistaeconomia.es/banco/7300_Introduction.pdf

Pacheco, N. (2005), recogido en Abascal Rojas, F. Marketing social y ética empresarial. Madrid: ESIC.

Pizzolante Negrón, I. (2009). De la responsabilidad social empresarial a la empresa socialmente responsable. Castellón: Ciencias Sociales.

Porter, M. E. y Kramer, M. R. (2006). Strategy and Society: The link between competitive advantage and Corporate Social Responsibility. Harvard Business Review, en CIRIEC-España, n. ${ }^{\circ} 53$.

Puterman, P. (2011). ¿Cómo se mide el valor de la RSC? Recuperado el 11 de agosto de 2015, de http:// www.blogresponsable.com/2011/05/como-se-mide-el-valor-de-la-rsc.html

Socorro, F. (2009). Ética, ética empresarial y responsabilidad social: un punto de vista. Recuperado el 12 de 
agosto de 2015, de http://www.degerencia.com/articulo/etica-etica-empresarial-y-responsabilidadsocial

Vañó Vañó, M.J (2004). Transparencia y nuevas tecnologías en las cooperativas de crédito. CIRIECEspaña, Revista de economía pública, social y cooperativa.

Vargas Sánchez, A. (2009). Responsabilidad Social Corporativa y Dirección de los RRHH. Universidad de Huelva. Recuperado el 05 de abril de 2013, de http://www.observatoriorrhhturismo.org/FilesDisp atcher;jsessionid=062BDE5FD145F3448FE277331 B50B07C?id=3661 Etipo= PublicacionAnexo. 
